\title{
Network Contagion vs. Spatial Contagion: The Diffusion of EHR Incentive Programs in Physician Networks
}

\author{
Meng-Hao Li \\ Schar School of Policy and Government \\ George Mason University \\ $\underline{\text { mli11@gmu.edu }}$
}

\author{
Naoru Koizumi \\ Schar School of Policy and Government \\ George Mason University \\ nkoizumi@gmu.edu
}

\begin{abstract}
The present study supported the network contagion theory that healthcare providers are more likely to adopt the Medicare and Medicaid Electronic Health Record (EHR) incentive program when their direct relations have more prior adopters. Spatial contagion, however, exhibits an opposite finding that healthcare providers geographically surrounded by more prior adopters are less likely to adopt the EHR incentive program. When taking both network contagion and spatial contagion into account, healthcare providers connected with more prior adopters within 30 miles are more likely to adopt the EHR incentive program. The findings enrich our understanding of how network contagion influences the diffusion of EHR incentive programs and how spatial contagion moderates the effects of network contagion on the diffusion of the EHR incentive programs.
\end{abstract}

\section{Introduction}

Health information technology (HIT) are the electronic systems that health care professionals and patients use to store, share and analyze health information. HIT has been widely applied to support healthcare systems and improve cost-effectiveness, efficiency, quality and safety of healthcare delivery [1]. The benefits of implementing HIT include automatizing labor-intensive work, minimizing human errors, speeding laboratory report deliveries, digitalizing patient records, and enhancing decision making and knowledge acquisition. Among those HIT, the electronic health records (EHRs) system is deemed as the most significant step in computerizing healthcare information systems. However, the adoption of the EHRs system had been less than 45 percent until 2009. The most common barriers for healthcare providers or

\footnotetext{
${ }^{1}$ https://www.cms.gov/Regulations-andGuidance/Legislation/EHRIncentivePrograms/RequirementsforPrevi ousYears
}

hospitals in adopting EHRs included misaligned incentives, limited purchasing power among healthcare providers, the viability of EHR products and companies, and lack of demonstrated value of EHRs in practice [2].

In 2011, the Medicare and Medicaid EHR Incentive Programs (now known as the Promoting Interoperability Programs) were established to facilitate the adoption and meaningful use of certified EHR technology in ambulatory practices and hospitals. The EHR incentive programs detail three stages that healthcare providers need to go through to be eligible for the monetary payments. The first stage expects the participants to establish the EHR infrastructure for the electronic extraction of clinical data. The second stage expects the participants to ensure the meaningful use of EHRs. The final stage expects the participants to produce better clinical outcomes and quality of care. ${ }^{1}$ The eligible participates (professionals and hospitals) are defined by the EHR incentive program. ${ }^{2}$ When the participants complete each stage, monetary payments are given.

The current program evaluation mostly relies on conventional survey methods to investigate obstacles that the participants have encountered [3], [4]. The survey evaluations assume that the respondents make their decisions on the EHR incentive program adoption independently by assessing its cost-benefit without taking other healthcare providers' behavior into account. The policy recommendations made based on the findings of such evaluation studies do not reflect the prior research on medical diffusions, which informed us, for instance, that healthcare provider networks are likely to influence the diffusion of new drugs through either direct (network contagion) or indirect healthcare provider relationships (structural equivalence) [5], [6]. However, structural equivalence (i.e., similar network positions, e.g., measured by a focal actor's distance relations to other actors) is useful typically when a

\footnotetext{
${ }^{2}$ https://www.cms.gov/Regulations-and-

Guidance/Legislation/EHRIncentivePrograms/Eligibility-
} 
network is well-connected, but it serves little utility when a network is fragmented (i.e., not able to calculate the distance between actors based on unconnected relations). It should be expected that a similar process would be observed in the diffusion/adoption of the EHR incentive programs in healthcare provider networks.

Moreover, spatial proximity or spatial interaction between healthcare providers would affect the adoption/diffusion process of the EHR incentive programs. Spatial proximity creates a space where mimetic behaviors and localized knowledge spillovers are possible and more likely through informal communications between healthcare providers [7]. The EHR incentive program information may be shared in healthcare provider networks and influences healthcare providers' decisions on program participation. Hence, this study aims to understand how healthcare providers' network contagion and spatial proximity collectively determine the adoption/participation of the EHR incentive programs.

The program participation data used in this study were downloaded from the Centers for Medicare and Medicaid Services, Department of Health and Human Services. The present study focused on 17,756 eligible healthcare providers between 2011 and 2015 in two hospital referral regions (HRR), Arlington areas (HRR code: 426), and Washington areas (HRR code:113). The provider patient-sharing networks, measured by referral relations, were constructed to examine how the program participation spreads in the healthcare provider networks. Survival analysis was used to estimate the program diffusion process.

\section{Literature reviews}

The adoption of technology as the adoption of an institution has been studied extensively in Information System research, e.g., enterprise resource planning systems or electronic trading systems [8]. For example, Sherer et al. used nationally representative data in 2008 and 2012 to examine how institutional pressures influence the diffusion of EHRs [9]. The findings indicated that the mimetic process was a critical predictor of EHRs adoption in a highly uncertain environment in 2008. The coercive process became a significant predictor of EHRs adoption in 2012 after HITECH was enacted in 2009. The normative process has continually influenced the adoption of EHRs before and after 2009. Another research surveyed 191 U.S. healthcare employees enrolled in the online healthcare MBA program, and the findings showed that the mimetic and coercive pressures do not have direct and significant effects on the level of EMR adoption. The normative and mimetic pressures have indirect effects on the level of EHR adoption through top management participation (i.e., mediation effect) [10]. The inconclusive results of institution pressures on EHRs adoption may be caused by different research designs, sampling methods, population, and measures of institutional pressures. In addition to the institutional perspective, other studies also found that the adoption process of EHRs is substantially varied by healthcare providers' specialties [11] and networks [12], hospital scale, hospital ownerships and locations (urban vs. rural) [3], [13], performance expectancy, facilitating or inhibiting conditions [14]. However, those studies paid little attention to the role of healthcare provider networks in the adoption/participation of the Medicare and Medicaid EHR Incentive Programs, which is deemed as an important stimulus for the increase of the EHR adoption rate in the U.S. Thus, this study attempts to examine how social contagion, spatial proximity, and the joint effect of social contagion and spatial proximity affect the adoption of EHR incentive program.

\subsection{Social contagion and network}

Social contagion theory is one of the underlying theories to elucidate how the spread of new ideas or practices is contingent on the way in which social proximity brings adopters and non-adopters together. Social proximity of innovations is expressed in two pathways to manage the uncertainty of costs and benefits: cohesion and structural equivalence [5], [6]. The cohesion approach argues that direct contacts and more frequent communication between adopters and non-adopters are a socialization process where adopters and non-adopters establish a normative understanding of the cost-benefit of adopting an innovation. When non-adopters are confronted with a need to make a decision in a vague situation, non-adopters would seek advice from whom they have established trust to discuss the innovation matter [15]. The contagion phenomena have been continuously found in the topics of the spread of options, attitudes, or behavior in communication networks [16]. Following this theory, our first hypothesis is:

Hypothesis 1: Network contagion is positively associated with the adoption of the EHR incentive program.

\subsection{Spatial proximity and network}

The structural equivalence model holds a contradictory perspective stating that people would compete for "survival" and mimic or learn from each other when they occupy similar social structure positions but are not necessarily have a direct contact. For example, two primary care physicians compete to 
serve as a new drug advisor in the healthcare market, or two graduate students, trained by the same academic advisor, compete for publications to earn their degrees. The structural equivalence model depicts that nonadopters are likely to become adopters when nonadopters maintain similar social positions as adopters [5]. The concept of structural equivalence has been extended to different measures of structural proximity. For example, Angst et al. investigated how prior adopters, social proximity, and spatial proximity influence the adoption of EHRs. Social proximity was operationalized as hospitals in the same health system, and spatial proximity was calculated based on the Euclidian distance between two hospitals' zip codes [17].

Spatial proximity as a predictor of the diffusion of adoption has demonstrated robust evidence. The arguments of spatial proximity follow a series of propositions. Companies consider location choices as a means of achieving economic benefits, such as the reduction of logistic or production costs, possibilities of recruiting skillful or low-cost employees, or opportunities of R\&D collaboration with universities. Because of chasing similar economic incentives, companies with homogeneous features are likely to cluster in the same area, e.g., industrial parks [7]. However, the mechanism of information diffusions among companies is not merely based on homogeneous characteristics. Both competition and interaction play different roles in facilitating the diffusion of innovations. From the competition viewpoint, clustered companies with similar features are likely to form a competitive environment. Spatial proximity creates more opportunities for managers to observe and notice the incidence of innovation adoption from their rival companies. The diffusion of innovations is motivated by competition, and the diffusion process is based on mimicking behavior. From the interaction perspective, spatial proximity creates more opportunities for employees to initiate informal interactions and information exchange with other employees from rival companies. The information may be conveyed back to those employees' companies and form a decision on innovations [18]-[20]. In addition, because tacit knowledge is not easy to be transferred from one to another, spatial proximity offers the opportunity to reduce the costs and facilitate complex forms of knowledge exchange and creation. Within a small boundary of an area, the frequent face-to-face interaction is a feasible means to distribute information and clarify whether the information is valuable [21][23]. Thus, in the process of knowledge transfer, spatial proximity serves as a resolution of overcoming institutional differences between organizations [22]. Geographically bounded and localized Individual links and face-to-face interactions significantly contribute to knowledge transfer [24]. Hence, we hypothesize that healthcare providers working with other adopters in the same area are more likely to adopt the EHR incentive program:

Hypothesis 2: Spatial proximity is positively associated with the adoption of the EHR incentive program

Moreover, a direct healthcare provider network connection coupling with spatial closeness increases the propensity for the program infection. Spatial proximity might serve as a moderator for the spread of the EHR incentive program from one healthcare provider to another healthcare provider with a direct connection:

Hypothesis 3: Spatial proximity is likely to accelerate the effect of network contagion on the adoption of the EHR incentive program.

\section{Methods}

\subsection{Data sources and management}

To understand the effects of network contagion and spatial proximity on the adoption of the EHR incentive programs, this study used data from five sources:

1. EHR Products Used for Meaningful Use Attestation Public Use File: The dataset contains healthcare provider's participation status in the EHR incentive program and their National Provider Identifier (NPI).

(https://dashboard.healthit.gov/datadashboard/documen tation/ehr-products-mu-attestation-data-

documentation.php)

2. Physician Shared Patient Patterns Data: The dataset contains referrals from one healthcare provider to another within a specific time frame in the Medicare program. National Provider Identifier is used to establish referral networks. In their study, Barnett et al. examined the relationship between healthcare provider self-report networks and Medicare claim-based networks in the Boston Hospital Referral Region [25]. The results concluded that two healthcare providers shared more Medicare patients are more likely to increase the recognition of referral relationships and advice relationships. Thus, using referral networks to construct healthcare provider networks is appropriate. (https://questions.cms.gov/faq.php?faqId=7977)

3. National Plan and Provider Enumeration System Data: The dataset is comprised of detailed profiles of healthcare and linked with NPIs.

(http://download.cms.gov/nppes/NPI_Files.html)

4. Hospital Referral Regions: The dataset "represents regional health care markets for tertiary 
medical care that generally requires the services of a major referral center. The regions were defined by determining where patients were referred for major cardiovascular surgical procedures and for neurosurgery."

(http://www.dartmouthatlas.org/tools/downloads.aspx)

5. TIGER/Line Shapefile, 2015, 2010 nation, U.S., 2010 Census 5-Digit ZIP Code Tabulation Area (ZCTA5) National: The 2010 shpefile is used to create a map covering Arlington and Washington hospital referral regions.

(https://catalog.data.gov/dataset/tiger-line-shapefile2015-2010-nation-u-s-2010-census-5-digit-zip-codetabulation-area-zcta5-na)

The present study extracted eligible NPIs registered in the Arlington (HRR code: 426) and Washington (HRR code: 113) hospital referral regions from the National Plan and Provider Enumeration System published by Dartmouth Atlas of Health. The boundary definitions of hospital referral regions are adjusted every year, and the most up-to-date version was published in 2014. Thus, we used the hospital referral region data from 2011 to 2014 and included all zip codes that appeared in any time periods in Arlington and Washington HRRs (Table 1). As the National Plan and Provider Enumeration System contains the NPIs' addresses, zip codes from the system and hospital referral regions were used as the crosswalk variable to link healthcare provider addresses to zip codes in Arlington and Washington HRRs (Figure 1). The total number of zip codes was 761 representing a total of 4,986 healthcare provider's business locations. Those business locations were geocoded to latitude and longitude coordinates using Census's web service. ${ }^{3}$ Of those 4,986 business locations, 600 addresses could not be found on the Census web. For those unfound locations, this study used Google Map to manually transform those addresses to latitude and longitude coordinates. The final data used in the analysis contained 17,756 healthcare providers and 3,418 locations.

\section{Table 1: Arlington and Washington hospital referral} regions

\begin{tabular}{|l|c|c|c|c|c|}
\hline HRR Year & 2011 & 2012 & 2013 & 2014 & Final Area \\
\hline \# of Zip Codes & 699 & 705 & 747 & 747 & 761 \\
\hline
\end{tabular}

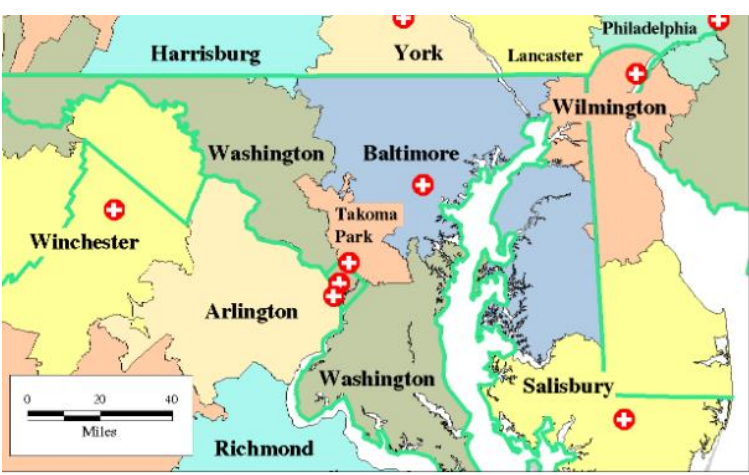

Figure 1: Map for hospital referral regions

To establish healthcare provider networks, the eligible NPIs were used to select referral claim data from the Physician Shared Patient Patterns data between 2011 and 2015. The network properties extracted from the data are summarized in Table 2. The original data shows that the number of edges downloaded from Physician Shared Patient Patterns. It should be noted that the number of referrals increased between 2011 and 2012 but decreased between 2012 and 2015. The network size is the total number of healthcare providers in the analysis. The total number of degrees is the number of all referrals made from a healthcare provider to other healthcare providers. The average degree represents the total number of degrees divided by the network size. The minimum degree reflects the number of healthcare providers who did not make Medicare claims in that year. The maximum degree represents the maximum number of claims that the healthcare providers made. The density represents all actual connections divided by all theoretically possible connections in the network. The density score ranges from 0 to 1 . A density score that is close to 1 indicating the network is denser. A density score is close to 0 indicating the network is loose. The healthcare provider networks here have low values of the density scores (0.003-0.006). This is expected because a larger network typically has a low density value than a smaller network where network members have a higher probability of reaching and knowing each other.

Table 2: Properties of healthcare provider networks

\begin{tabular}{|l|r|r|r|r|r|}
\hline & \multicolumn{1}{|c|}{$\mathbf{2 0 1 1}$} & \multicolumn{1}{|c|}{$\mathbf{2 0 1 2}$} & \multicolumn{1}{|c|}{$\mathbf{2 0 1 3}$} & \multicolumn{1}{|c|}{$\mathbf{2 0 1 4}$} & \multicolumn{1}{|c|}{$\mathbf{2 0 1 5}$} \\
\hline Network size & 17,756 & 17,756 & 17,756 & 17,756 & 17,756 \\
\hline $\begin{array}{l}\text { Total number } \\
\text { of degrees }\end{array}$ & $9,48,787$ & 981,447 & 973,305 & $1,012,412$ & 458,768 \\
\hline $\begin{array}{l}\text { Average } \\
\text { degree }\end{array}$ & 53 & 55 & 55 & 57 & 26 \\
\hline Min degree & 0 & 0 & 0 & 0 & 0 \\
\hline Max degree & 1,413 & 1,445 & 1,394 & 1,388 & 866 \\
\hline Density & 0.0060 & 0.0062 & 0.0062 & 0.0064 & 0.0029 \\
\hline
\end{tabular}

The eligible 17,756 NPIs in the Arlington and Washington hospital referral regions were used to select

\footnotetext{
${ }^{3}$ https://geocoding.geo.census.gov/
} 
healthcare providers who participated in the stage one of the EHR incentive programs from the EHR Products Used for Meaningful Use Attestation Public Use File. Of those 17,756 NPIs, 5,092 NPIs participated in the EHR incentive program.

\subsection{Measurements}

Program Adoption is a binary variable measuring whether a healthcare provider adopted stage one of the EHR incentive program. " 1 " indicates that the provider adopted the program while " 0 " indicates otherwise.

Business Size is a binary variable measuring whether an NPI business address has more than 10 healthcare providers or less than 10 . " 1 " represents that a healthcare provider's business address has more than 10 healthcare providers, while " 0 " represents that a healthcare provider's business address has 10 or less than 10 healthcare providers.

Network Contagion measures the probability of a healthcare provider being influenced by other connected healthcare providers for the decision to adopt the EHR incentive program. The variable is calculated by the summation of prior adopter/non-adopter multiplied by weighted connections. The weighted values are proportional to the healthcare provider's direct connections.

Spatial Contagion is used to measure the spatial proximity effect of adopters on susceptible healthcare providers. Spatial Contagion is the number of prior adopters within 30 miles of the healthcare provider's business location. The decision for the 30 miles is arbitrary. A patient's maximum distance to visit primary care providers or specialists varies by state and whether the provider is located in an urban or rural area (Table 3 ). Nonetheless, the number of primary care providers is larger than that of specialists, and most providers are located in urban areas, it may be reasonable to set the maximum distance based on the primary care providers in urban areas. Thus, the present study set the maximum distance as 15 miles for the Arlington HRR, reflecting that patients in the HRR are able to visit healthcare providers within 15 miles. In other words, if a patient lives in a place between two healthcare providers, an optimal maximum distance between two providers is 30 miles, allowing the patient to visit them within 15 miles. Besides, only Virginia provides patients' traveling information about visiting primary care providers and specialists. In order to create a consistent measure for the two HRRs, the present study applied Virginia's standards to both Arlington and Washington HRRs.

Table 3: Maximum Distance or Time an Enrollee Should Have to Travel to See a Provider (HHS, 2014) \begin{tabular}{|l|l}
\hline Primary Care Providers & Specialists \\
\hline
\end{tabular}

\begin{tabular}{|c|c|c|}
\hline $\begin{array}{l}\text { District of } \\
\text { Columbia }\end{array}$ & $\begin{array}{l}\text { Within } 30 \text { minutes' travel time } \\
\text { via public } \\
\text { transportation or within } 5 \text { miles }\end{array}$ & No standard \\
\hline Maryland & $\begin{array}{l}\text { Urban: Within } 30 \text { minutes or } \\
10 \text { miles } \\
\text { Rural: Within } 30 \text { minutes or } 30 \\
\text { miles }\end{array}$ & No standard \\
\hline Virginia & $\begin{array}{l}\text { Urban: Within } 30 \text { minutes or } \\
15 \text { miles } \\
\text { Rural: Within } 60 \text { minutes or } 30 \\
\text { miles }\end{array}$ & $\begin{array}{l}\text { Urban: Within } \\
30 \text { miles } \\
\text { Rural: Within } 60 \\
\text { miles }\end{array}$ \\
\hline
\end{tabular}

\subsection{Model specialization}

Because the program adoption variable is a timeevent data with right censoring, the hazard modeling is used as the main statistical method to analyze the data. The analysis also includes time-varying variables (i.e. network contagion and spatial proximity variables). Thus, the random-effects parametric survival model with the Weibull survival distribution (time duration distribution) was chosen to test the hypotheses. The healthcare providers in the same location are likely to have erroneously small standard errors due to data correlations. Thus, the clustered standard errors are used to correct the estimation, which yields 3,418 clusters (business locations) [26]-[29].

\section{Analysis and results}

\subsection{Descriptive statistics}

Table 4 shows that $63 \%$ of healthcare providers are in the business locations where there are more than 10 healthcare providers, while $37 \%$ of healthcare providers are located in locations with less than 10 healthcare providers. The EHR adoption rate was $4 \%$ in 2011 , increased to $12 \%$ in 2012 , and then decreased to $4 \%$ in 2014 and to $2 \%$ in 2015 . The total adoption rate was $28.68 \%$, and the number of adoption was 5,092. The cumulative adoption rate is shown in Figure 4. Besides, the correlation coefficient between network contagion and spatial contagion is $0.2376(\mathrm{P}<0.01)$.

Table 4: Descriptive Statistics

\begin{tabular}{lrrrrr}
\hline Variable & $\mathrm{N}$ & Mean/\% & S.D. & Min & Max \\
\hline Business Size (\% of large) & 17,756 & $63 \%$ & 0.48 & 0 & 1 \\
Adoption rate in 2011 (\%) & 17,756 & $4 \%$ & 0.20 & 0 & 1 \\
Adoption rate in 2012(\%) & 17,756 & $12 \%$ & 0.33 & 0 & 1 \\
Adoption rate in 2013 (\%) & 17,756 & $6 \%$ & 0.24 & 0 & 1 \\
Adoption rate in 2014 (\%) & 17,756 & $4 \%$ & 0.20 & 0 & 1 \\
Adoption rate in 2015 (\%) & 17,756 & $2 \%$ & 0.14 & 0 & 1 \\
Network Contagion in 2011 & 17,756 & 0.05 & 0.12 & 0 & 1
\end{tabular}




\begin{tabular}{lrrrrr} 
Network Contagion in 2012 & 17,756 & 0.19 & 0.25 & 0 & 1 \\
Network Contagion in 2013 & 17,756 & 0.27 & 0.31 & 0 & 1 \\
Network Contagion in 2014 & 17,756 & 0.31 & 0.33 & 0 & 1 \\
Network Contagion in 2015 & 17,756 & 0.27 & 0.34 & 0 & 1 \\
Spatial Contagion in 2011 & 17,756 & 519.93 & 204.09 & 15 & 654 \\
Spatial Contagion in 2012 & 17,756 & 1955.39 & 727.56 & 45 & 2482 \\
Spatial Contagion in 2013 & 17,756 & 2677.47 & 1001.76 & 54 & 3364 \\
Spatial Contagion in 2014 & 17,756 & 3161.33 & 1187.93 & 67 & 3999 \\
Spatial Contagion in 2015 & 17,756 & 3406.26 & 1281.29 & 69 & 4317 \\
\hline
\end{tabular}

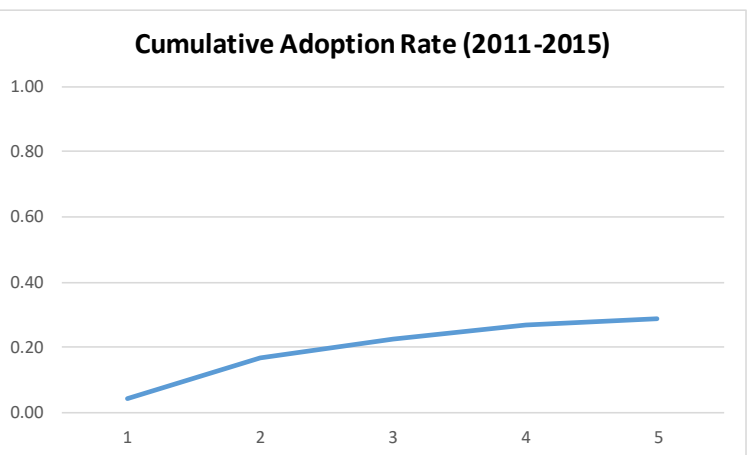

Figure 4: Cumulative Program Adoption Rate from 2011 to 2015

\subsection{Hazard model analysis}

Table 5 summarizes the results of the hazard model analyses with different predictors for the adoption of the EHR incentive program. The first model shows that location size does not have a significant effect on the adoption. The second model predicts that the adoption rate would increase $177 \%$ with a unit increase in the network contagion measure. The adoption rate would decrease by $0.05 \%$ with a unit increase in spatial contagion. The fourth model includes all three predictors. The results indicate that all predictors are statistically significant. Business size and network contagion are positively associated with the adoption of the EHR incentive program, but spatial contagion is negatively associated. The fact that the business size is statistically insignificant in the first model while it has a statistically significant positive effect in the third model indicates that business size is likely to have interaction effects with other predictors.

In the fifth model, we explored whether business size accelerates the effects of network contagion and spatial contagion on the adoption of the EHR incentive program (Hypothesis 3). The interaction effect of business size and spatial contagion was not statistically significant, while the other two interaction effects were statistically significant. Thus, the interaction effect of business size and spatial contagion was subsequently dropped from the fifth model. In the sixth model, both interaction terms were statistically significant, indicating that a large business size coupling with a high value of network contagion tends to lead to EHR adoption compared to a small business size with a higher value of network contagion. Likewise, a higher value of network contagion coupling with a higher value of spatial contagion tends to promote the adoption EHR incentive program compared to a lower value of network contagion coupling with a lower value of spatial contagion.

Finally, there are several parametric distributions, which can be used to specify the hazard model. To ensure that the Weibull distribution is appropriate, we tested the goodness of fit of Gamma, Loglogistic and Lognormal distributions for the last model (Table 6). The table shows that the Weibull distribution has the best goodness of fits in terms of AIC and BIC.

Table 5: Random effects Weibull regression

\begin{tabular}{|c|c|c|c|}
\hline & $\begin{array}{c}1 \\
\text { Hazard } \\
\text { Ratio } \\
\text { (SE) } \\
\end{array}$ & $\begin{array}{c}2 \\
\text { Hazard } \\
\text { Ratio } \\
\text { (SE) } \\
\end{array}$ & $\begin{array}{c}3 \\
\text { Hazard } \\
\text { Ratio } \\
\text { (SE) } \\
\end{array}$ \\
\hline BusinessSize & & & \\
\hline & $(0.0831)$ & & \\
\hline NetworkContagion ${ }_{t-1}$ & & $\begin{array}{l}2.7679 * * * \\
(0.1728)\end{array}$ & \\
\hline SpatialContagion $_{t-1}$ & & & $\begin{array}{l}0.9995^{* * * *} \\
(0.0000)\end{array}$ \\
\hline Constant & $\begin{array}{l}0.0054 * * * \\
(0.0003)\end{array}$ & $\begin{array}{l}0.0044 * * * \\
(0.0003)\end{array}$ & $\begin{array}{l}0.0145^{* * * *} \\
(0.0013)\end{array}$ \\
\hline Log pseudolikelihood & -19812 & $-19502 * * *$ & $-18698 * * *$ \\
\hline Observations & 71,024 & 71,024 & 71,024 \\
\hline Groups & 17,756 & 17,756 & 17,756 \\
\hline
\end{tabular}

$*_{\mathrm{p}}<0.05 ; * * \mathrm{p}<0.01 ; * * \mathrm{p}<0.001 ; \mathrm{SE}$ adjusted for 3,418 clusters (locations)

Table 5: Random effects Weibull regression (cont.)

\begin{tabular}{|c|c|c|c|}
\hline & $\begin{array}{c}4 \\
\text { Hazard } \\
\text { Ratio } \\
\text { (SE) } \\
\end{array}$ & $\begin{array}{c}5 \\
\text { Hazard } \\
\text { Ratio } \\
(\mathrm{SE}) \\
\end{array}$ & $\begin{array}{c}6 \\
\text { Hazard } \\
\text { Ratio } \\
(\mathrm{SE}) \\
\end{array}$ \\
\hline \multirow[t]{2}{*}{ BusinessSize } & $1.3531 * *$ & $1.8633^{* * *}$ & $1.5670^{* * * *}$ \\
\hline & $(0.1332)$ & $(0.3248)$ & $(0.1794)$ \\
\hline \multirow{2}{*}{ NetworkContagion ${ }_{t-1}$} & $2.3715^{* * *}$ & $1.5275^{* *}$ & $1.5548 * *$ \\
\hline & $(0.2004)$ & $(0.2069)$ & $(0.2046)$ \\
\hline \multirow[t]{2}{*}{ SpatialContagion $_{t-l}$} & $0.9995^{* * *} *$ & $0.9995^{* * *}$ & $0.9994 * * *$ \\
\hline & $(0.0000)$ & $(0.0000)$ & $(0.0000)$ \\
\hline BusinessSize $\mathrm{x}$ & & $0.7074^{*}$ & $0.6850^{* * *}$ \\
\hline NetworkContagion $t-1$ & & $(0.0971)$ & $(0.0952)$ \\
\hline
\end{tabular}




\begin{tabular}{|c|c|c|c|}
\hline BusinessSize $\mathrm{x}$ & & 0.9999 & \\
\hline SpatialContagion $_{t-1}$ & & $(0.0000)$ & \\
\hline NetworkContagion $_{t-1} \mathrm{x}$ & & $1.0003 * * *$ & $1.0003 * * *$ \\
\hline SpatialContagion $_{t-1}$ & & $(0.0001)$ & $(0.0001)$ \\
\hline \multirow[t]{2}{*}{ Constant } & $0.0096^{* * *}$ & $0.0098^{* * *}$ & $0.0109 * * *$ \\
\hline & $(0.0008)$ & $(0.0009)$ & $(0.0009)$ \\
\hline Log pseudolikelihood & $-18413^{* * * *}$ & $-18341^{* * * *}$ & $-18353 * * *$ \\
\hline Observations & 71,024 & 71,024 & 71,024 \\
\hline Groups & 17,756 & 17,756 & 17,756 \\
\hline
\end{tabular}

$* \mathrm{p}<0.05 ; * * \mathrm{p}<0.01 ; * * * \mathrm{p}<0.001 ;$ SE adjusted for 3,418 clusters (locations)

Table 6: Cross-Validation Tests

\begin{tabular}{|c|c|c|c|c|}
\hline & $\begin{array}{c}\text { Weibull } \\
\text { Distribution }\end{array}$ & $\begin{array}{c}\text { Gamma } \\
\text { Distribution }\end{array}$ & $\begin{array}{c}\text { Loglogistic } \\
\text { Distribution }\end{array}$ & $\begin{array}{c}\text { Lognormal } \\
\text { Distribution }\end{array}$ \\
\hline AIC & 36712.45 & 44762.89 & 44956.41 & 43886.89 \\
\hline BIC & 36778.21 & 44828.65 & 45022.17 & 43952.65 \\
\hline
\end{tabular}

\section{Discussion}

The present study is the first research that used healthcare provider referral networks in panel data to examine the factors influencing the diffusion of the EHR incentive program in Arlington and Washington Hospital Referral Regions [30]. The results support the first and third hypotheses but did not support the second hypothesis. The findings indicate that healthcare providers exposed to more prior adopters in referral relations are more likely to adopt the EHR incentive program. Nevertheless, spatial contagion is negatively associated with the adoption of the EHR incentive program, indicating that healthcare providers geographically surrounded with more prior adopters within 30 miles are less likely to adopt the EHR incentive program. When specializing spatial contagion as a moderator, healthcare providers exposed to more prior adopters within 30 miles are more likely to adopt the EHR incentive program. Another intriguing finding is that business size matters, but only when network contagion is considered. A susceptible healthcare provider with a large business size connected with more EHR incentive program adopters tends to increase the likelihood of the program adoption. This often happens when non-adopters and adopters are affiliated with the same health care system.

The analytical approach and the findings of the present study have several implications. First, the analytical framework used in the present study can be applied to understand other diffusion phenomena including that of other health policy programs, new drugs or therapies diffusion. Prior research explored the association between properties of healthcare provider referral networks and patient characteristics [31], while other researchers examined how healthcare provider referral networks are associated with health care patterns [25]. For policymakers, the network analysis approach can be used as guidance to identify key providers that may facilitate the policy implementation process [32]-[34]. Such a study, however, would require collecting more data on healthcare provider characteristics, e.g., whether the provider is a specialist or a primary care provider.

Second, the spatial proximity theory is not supported in our findings. One possible explanation is the inappropriate measure of the variable. In this study, spatial proximity is measured by spatial contagion and is defined as the number of prior adopters within 30 miles of the provider's location. Although 30 miles may be appropriate for providers in the urban area in Northern Virginia (Arlington HRR), it may be too large for providers in the urban areas in Southern Maryland or the District of Columbia (Washington HRR). Further investigation on the optimal distance is warranted as well as a sensitivity analysis with different values for the maximum distance.

Third, the business size in our study plays a significant role in facilitating the network contagion process. Healthcare providers with a large business size can be viewed as working in large hospitals, i.e., large hospitals are expected to have a higher capacity to implement EHR systems or handle the administrative process of the program participation. When those healthcare providers in a large hospital system are exposed to more prior adopters via referral networks, the peer pressure will influence their decisions on the program adoption. In contrast, healthcare providers in a small location tend to have less capacity to implement EHR or to handle the administrative process. Even though peer pressure can influence those healthcare providers' decisions to adopt the program, lack of organizational resources may hamper the program adoption. Furthermore, the matter of a business size depends on the unit of analysis. In practice, the EHR incentive program may be adopted by hospitals and then spreads to healthcare providers. However, this study assumed that healthcare providers are the decisionmakers of the program. Future investigation may aggregate the data to estimate whether the network contagion and spatial contagion still contribute to the adoption of the EHR incentive program at the hospital level.

\section{Limitations}

At present, several limitations remain unsolved and deserve further progress. First, this study chose Arlington and Washington HRRs as a case study to explore how the EHR incentive programs diffuse among 
healthcare provider networks. The analysis results are unavoidably limited to these two areas and are not sufficient to represent the nationwide diffusion of the program. Second, the healthcare provider network data are only available between 2011 and 2015. The data period restricts the time window that we could analyze. Third, this study has not yet collected the characteristics (e.g., locations of urbanization or cognition about the EHR program) of healthcare providers. Those factors are likely to contribute to the diffusion of the EHR incentive program. Finally, the model specification has not yet balanced data or controlled for instrumental variables to make causal inferences. The conclusion of this study should be only used to infer the association between the independent variables and the dependent variable.

\section{References}

[1] P. G. Shekelle, S. C. Morton, and E. B. Keeler, "Costs and benefits of health information technology," Evid. ReportTechnology Assess., no. 132, pp. 1-71, Apr. 2006, doi: 10.23970/ahrqepcerta132.

[2] B. Middleton, W. E. Hammond, P. F. Brennan, and G. F. Cooper, "Accelerating U.S. EHR Adoption: How to Get There From Here. Recommendations Based on the 2004 ACMI Retreat," J. Am. Med. Inform. Assoc., vol. 12, no. 1, pp. 13-19, Jan. 2005, doi: 10.1197/jamia.M1669.

[3] J. Adler-Milstein et al., "More Than Half of US Hospitals Have At Least A Basic EHR, But Stage 2 Criteria Remain Challenging For Most," Health Aff. (Millwood), vol. 33, no. 9, pp. 1664-1671, Sep. 2014, doi: 10.1377/hlthaff.2014.0453.

[4] J. Adler-Milstein et al., "Electronic Health Record Adoption In US Hospitals: Progress Continues, But Challenges Persist," Health Aff. (Millwood), vol. 34, no. 12, pp. 2174-2180, Dec. 2015, doi: 10.1377/hlthaff.2015.0992.

[5] R. S. Burt, "Social Contagion and Innovation: Cohesion versus Structural Equivalence," Am. J. Sociol., vol. 92, no. 6, pp. 1287-1335, 1987, doi: $10.2307 / 2779839$.

[6] P. V. Marsden and N. E. Friedkin, "Network Studies of Social Influence," Sociol. Methods Res., vol. 22, no. 1, pp. 127-151, Aug. 1993, doi: 10.1177/0049124193022001006.

[7] C. Autant-Bernard, J. Mairesse, and N. Massard, "Spatial knowledge diffusion through collaborative networks*," Pap. Reg. Sci., vol. 86, no. 3, pp. 341350, 2007, doi: 10.1111/j.1435-5957.2007.00134.x.

[8] M. Mignerat and S. Rivard, "Positioning the Institutional Perspective in Information Systems Research," J. Inf. Technol., vol. 24, no. 4, pp. 369391, Dec. 2009, doi: 10.1057/jit.2009.13.

[9] S. A. Sherer, C. D. Meyerhoefer, and L. Peng, "Applying institutional theory to the adoption of electronic health records in the U.S.," Inf. Manage., vol. 53, no. 5, pp. 570-580, Jul. 2016, doi: 10.1016/j.im.2016.01.002.

[10] V. Gopalakrishna-Remani, R. P. Jones, and K. M. Camp, "Levels of EMR Adoption in U.S. Hospitals: An Empirical Examination of Absorptive Capacity, Institutional Pressures, Top Management Beliefs, and Participation," Inf. Syst. Front., vol. 21, no. 6, pp. 1325-1344, Dec. 2019, doi: 10.1007/s10796-0189836-9.

[11] M. V. Boland et al., "Adoption of Electronic Health Records and Preparations for Demonstrating Meaningful Use: An American Academy of Ophthalmology Survey," Ophthalmology, vol. 120, no. 8, pp. 1702-1710, Aug. 2013, doi: 10.1016/j.ophtha.2013.04.029.

[12] K. Zheng, R. Padman, D. Krackhardt, M. P. Johnson, and H. S. Diamond, "Social networks and physician adoption of electronic health records: insights from an empirical study," J. Am. Med. Inform. Assoc., vol. 17, no. 3, pp. 328-336, May 2010, doi: 10.1136/jamia.2009.000877.

[13] J. Adler-Milstein, A. J. Holmgren, P. Kralovec, C. Worzala, T. Searcy, and V. Patel, "Electronic health record adoption in US hospitals: the emergence of a digital 'advanced use' divide," J. Am. Med. Inform. Assoc., vol. 24, no. 6, pp. 1142-1148, Nov. 2017, doi: 10.1093/jamia/ocx080.

[14] J. Li, A. Talaei-Khoei, H. Seale, P. Ray, and C. R. MacIntyre, "Health Care Provider Adoption of eHealth: Systematic Literature Review," Interact. J. Med. Res., vol. 2, no. 1, p. e7, 2013, doi: 10.2196/ijmr.2468.

[15] N. E. Friedkin, "Social Cohesion," Annu. Rev. Sociol., vol. 30, no. 1, pp. 409-425, Jul. 2004, doi: 10.1146/annurev.soc.30.012703.110625.

[16] N. A. Christakis and J. H. Fowler, "Social contagion theory: examining dynamic social networks and human behavior," Stat. Med., vol. 32, no. 4, pp. 556577, 2013, doi: 10.1002/sim.5408.

[17] C. M. Angst, R. Agarwal, V. Sambamurthy, and K. Kelley, "Social Contagion and Information Technology Diffusion: The Adoption of Electronic Medical Records in U.S. Hospitals," Manag. Sci., vol. 56, no. 8, pp. 1219-1241, Jun. 2010, doi: $10.1287 /$ mnsc. 1100.1183 .

[18] W. D. Berry and B. Baybeck, "Using Geographic Information Systems to Study Interstate Competition," Am. Polit. Sci. Rev., vol. 99, no. 4, pp. 505-519, Nov. 2005, doi: 10.1017/S0003055405051841.

[19] F. S. Berry and W. D. Berry, "State Lottery Adoptions as Policy Innovations: An Event History Analysis," Am. Polit. Sci. Rev., vol. 84, no. 2, pp. 395-415, Jun. 1990, doi: 10.2307/1963526.

[20] S. Breschi and F. Lissoni, "Knowledge spillovers and local innovation systems: a critical survey," Ind. Corp. Change, vol. 10, no. 4, pp. 975-1005, 2001.

[21] J. S. Katz, "Geographical proximity and scientific collaboration," Scientometrics, vol. 31, no. 1, pp. 3143, Sep. 1994, doi: 10.1007/BF02018100.

[22] R. Ponds, F. van Oort, and K. Frenken, "The geographical and institutional proximity of research 
collaboration," Pap. Reg. Sci., vol. 86, no. 3, pp. 423443, Aug. 2007, doi: 10.1111/j.1435-

5957.2007.00126.x.

[23] J. Hoekman, K. Frenken, and F. Van Oort, "The geography of collaborative knowledge production in Europe," Ann. Reg. Sci., vol. 43, no. 3, pp. 721-738, 2009.

[24] A. J. Salter and B. R. Martin, "The economic benefits of publicly funded basic research: a critical review," Res. Policy, vol. 30, no. 3, pp. 509-532, Mar. 2001, doi: 10.1016/S0048-7333(00)00091-3.

[25] M. L. Barnett, B. E. Landon, A. J. O’Malley, N. L. Keating, and N. A. Christakis, "Mapping Physician Networks with Self-Reported and Administrative Data," Health Serv. Res., vol. 46, no. 5, pp. 15921609, 2011, doi: 10.1111/j.1475-6773.2011.01262.x.

[26] M. Arellano, Panel data econometrics. Oxford University Press, 2003.

[27] M. Cleves, Gould, W. W., and Marchenko, Y. V., An introduction to survival analysis using Stata. Stata Press, 2008.

[28] J. H. Stock and M. W. Watson, "HeteroskedasticityRobust Standard Errors for Fixed Effects Panel Data Regression," Econometrica, vol. 76, no. 1, pp. 155174, Jan. 2008, doi: 10.1111/j.00129682.2008.00821.x.
[29] J. Wu, F. W. Crawford, D. A. Kim, D. Stafford, and N. A. Christakis, "Exposure, hazard, and survival analysis of diffusion on social networks," Stat. Med., vol. 37 , no. 17 , pp. 2561-2585, 2018, doi: $10.1002 / \operatorname{sim} .7658$.

[30] S.-H. Bae, A. Nikolaev, J. Y. Seo, and J. Castner, "Health care provider social network analysis: A systematic review," Nurs. Outlook, vol. 63, no. 5, pp. 566-584, Sep. 2015, doi: 10.1016/j.outlook.2015.05.006.

[31] B. E. Landon et al., "Variation in Patient-Sharing Networks of Physicians Across the United States," JAMA, vol. 308, no. 3, pp. 265-273, Jul. 2012, doi: 10.1001/jama.2012.7615.

[32] T. W. Valente, L. A. Palinkas, S. Czaja, K.-H. Chu, and C. H. Brown, "Social Network Analysis for Program Implementation," PLOS ONE, vol. 10, no. 6, p. e0131712, Jun. 2015, doi: 10.1371/journal.pone.0131712.

[33] T. W. Valente, "Network Interventions," Science, vol. 337, no. 6090, pp. 49-53, Jul. 2012, doi: 10.1126/science. 1217330 .

[34] A. Thakkar et al., "Network characteristics of a hypertension referral system in western kenya," Eur. Heart J., vol. 40, no. Supplement_1, Oct. 2019, doi: 10.1093/eurheartj/ehz746.0967. 